\title{
An Early Experience of Stapled Hemorrhoidectomy in a Medical College Setting
}

\author{
Mushtaq Chalkoo*, Shahnawaz Ahangar, Naseer Awan, Varun Dogra, Umer Mushtaq, \\ Hilal Makhdoomi \\ Department of General Surgery, Government Medical College, Srinagar, India \\ Email: ${ }^{*}$ mushtaq chalkoo@rediffmail.com
}

Received 13 April 2015; accepted 18 May 2015; published 26 May 2015

Copyright (C) 2015 by authors and Scientific Research Publishing Inc.

This work is licensed under the Creative Commons Attribution International License (CC BY).

http://creativecommons.org/licenses/by/4.0/

(c) (i) Open Access

\section{Abstract}

Background: Stapled hemorrhoidectomy, popularly known as Longo technique is in use for the treatment of hemorrhoids since its first description to surgical fraternity in the world congress of endoscopic surgeons in 1998. Objectives: To evaluate the feasibility, patient acceptance, recurrence and results of stapled haemorrhoidectomy in our early experience. Methods: Between Jan 2012 and Dec 2013, 42 patients with symptomatic GRADE III and IV hemorrhoids were operated by stapled hemorrhoidectomy by a single surgeon at our surgery department. The evaluation of this technique was done by assessing the feasibility of the surgery; and recording operative time, postoperative pain, complications, hospital stay, return to work and recurrence. Results: All the procedures were completed successfully. The mean (range) operative time was 30 (20 - 45) $\mathrm{min}$. The blood loss was minimal. Mean (range) length of hospitalization for the entire group was 1 (1 3) days. Only 3 patients required more than 1 injection of diclofenac $(75 \mathrm{mg})$ while as rest of the patients were quite happy switching over to oral diclofenac (50 mg) just after a single parenteral dose. All the patients returned to their routine work in less than a week's time. The mean (range) follow-up was $6(4$ - 12) months. There were no major intraoperative or postoperative complications except for retention of urine in 8 patients. The patients are still on regular follow-up and have not had recurrence as yet. Conclusion: Stapled hemorrhoidectomy technique is a safe alternative to the traditional Milligan-Morgan technique. It can be performed as an office procedure, is well tolerated by patients and is cost effective than conventional surgical therapy.

\section{Keywords}

Hemorrhoids, Surgical Treatment, Longo Technique

\footnotetext{
*Corresponding author.
}

How to cite this paper: Chalkoo, M., Ahangar, S., Awan, N., Dogra, V., Mushtaq, U. and Makhdoomi, H. (2015) An Early Experience of Stapled Hemorrhoidectomy in a Medical College Setting. Surgical Science, 6, 214-220. 


\section{Introduction}

Hemorrhoids are one of the most common benign anorectal problems seen worldwide. The role of surgery for treatment comes in grade III/IV hemorrhoids [1] [2]. The Milligan-Morgan technique has been a reference technique against which all techniques are judged. Minimal invasive procedure for hemorrhoids (commonly known as piles) has been gaining importance since the performance of first presentation made by Longo in 1998. It suits as an alternative to Ferguson and Milligan-Morgan techniques for the operative management of hemorrhoidal disease. Longo method or Stapled Hemmorhoidectomy is done by the transanal introduction of circular stapler to excise redundant rectal mucosa. It is used as a day care procedure with minimal postoperative bleeding and pain with an additional benefit of early return to work. It has already been established as a gold standard treatment for hemorrhoids in many countries. We took up this study at our hospital to evaluate the feasibility, patient acceptance, recurrence and results of stapled haemorrhoidectomy.

\section{Material and Methods}

We took up this study in our department as an early experience with this new technique; stapled hemorrhoidectomy on prospective cohort of 42 patients between January 2012 and December 2013. The patients with symptomatic grade III/IV hemorrhoids were specifically chosen for the procedure. The demographic details and symptoms are given in Table 1 . The present study evaluates the clinical outcome of stapled hemorrhoidectomy with regards to postoperative morbidity like pain, bleeding, analgesic requirement and recurrence. We excluded all the patients who presented with thrombosed hemorrhoids, concomitant perianal fistula, anal fissures or abscess. All patients were admitted on the day of surgery. 25 patients were done under spinal anesthesia while the rest 17 were done general anesthesia.

\section{Operative Technique}

The operative position of the patients selected was lithotomy and all patients received parenteral antibiotic dose at the time of induction of anesthesia. After taking all aseptic precautions, the procedure of stapled hemorrhoidectomy was performed according to Longo's technique [Figure 1]. A circular anal dilator was placed and fixed to the skin [Figure 2]. A purse string suture of 2-0 prolene was inserted at about 4 centimeters above the dentate line catching only the mucosa and sub mucosa with the help of a purse-string suture anoscope [Figure 3]. The distance of the purse string suture from the dentate line should be directly proportional to the extent of the prolapse so as to position the staple line at least 2cms above the dentate line [Figure 4]. A well lubricated 33mm stapling instrument with a fully opened position was inserted and the anvil was positioned above the purse string. The purse-string was snugged down on the shaft of the stapler and tied [Figure 5]. The stapler was closed and fired and held closed for 30 seconds to aid in homeostasis [Figure 6]. In females posterior vaginal wall was checked before firing the stapler to prevent entrapment. The stapler was then one turn anticlockwise opened to its maximum and gently withdrawn. The staple line was inspected for bleeding and any spurting point was over sewn with polygalactin 3-0. At the end of operation, anal canal was packed with gauze dressing impregnated with $2 \%$ Lignocaine gel which was removed in the evening of day of surgery. The doughnut was checked for its completeness and sent for histopathology [Figure 7]. Our patients were routinely kept for overnight in the hospital barring a few who were discharged on second or third postoperative day. We routinely recommended sitz bath in the first postoperative day and one week postop antibiotics, analgesics and stool softeners.

\section{Results}

42 patients underwent stapler hemorrhoidectomy for hemorrhoids in our department at Medical College since Jan 2012 to Dec 2013. The group comprised 35 men and 7 women in the mean age range of 40 years (30 - 70 years). The patients graded III and IV on proctoscopy were subjected to this stapled treatment. The mean operative time was $30 \mathrm{~min}$ (20 - $45 \mathrm{~min}$ ). We did not encounter any major intraoperative complication. 8 of our patients required catheterization for the retention of urine. There was no case of postoperative bleeding; 7 complained of postoperative soiling on day1, 4 had constipation (Table 2). Mean (range) length of hospitalization for the entire group was $1(1$ - 3) days. None of our patients presented with significant bleeding and no transfusion was required in any. The patients were followed upto 6 weeks' time on regular basis. At around 2 weeks follow-up, majority of our patients were satisfied and had no complaints about the surgery and its results how 


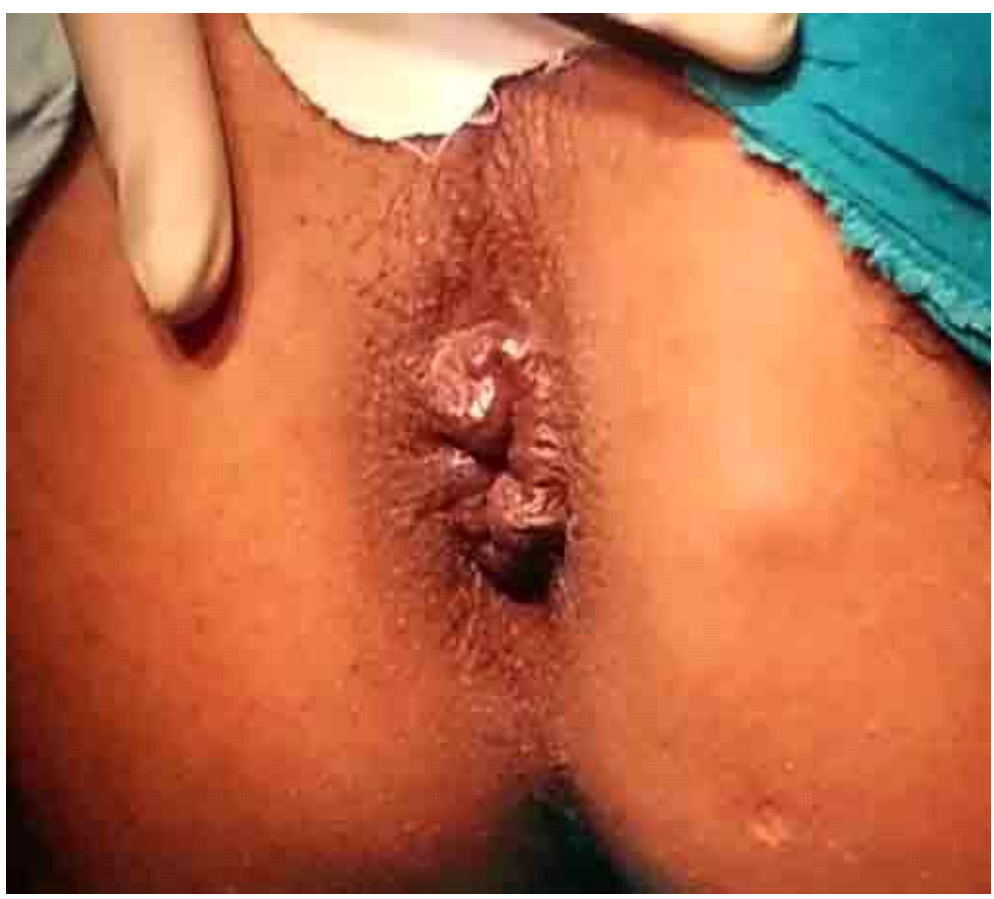

Figure 1. Showing hemorrhoids after draping the perineum.

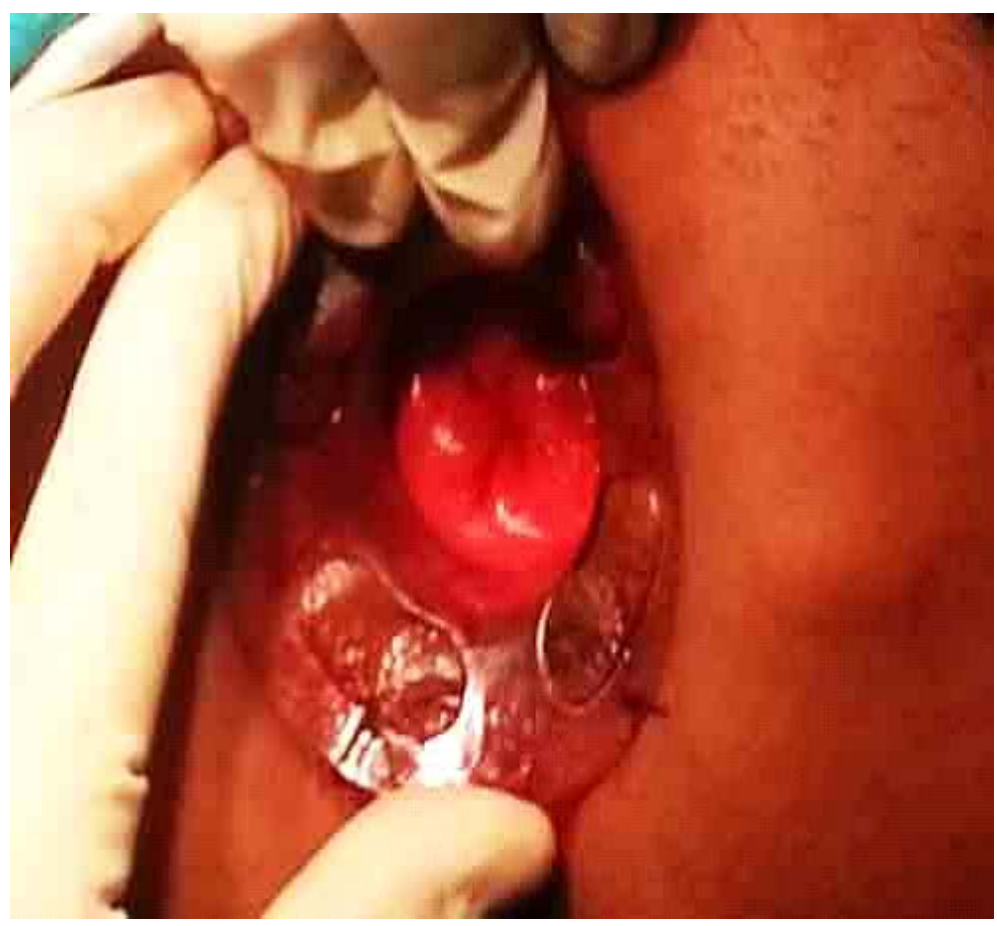

Figure 2. Circular anal dilator fixed to the skin with sutures.

ever, 15 of them complained of external pile masses left over; 10 has mild pain and/or burning sensation on defecation and 9 patients had pruritis ani.

\section{Discussion}

Hemorrhoid is one of the commonest ailments of mankind. Many treatments have been advocated and tested 


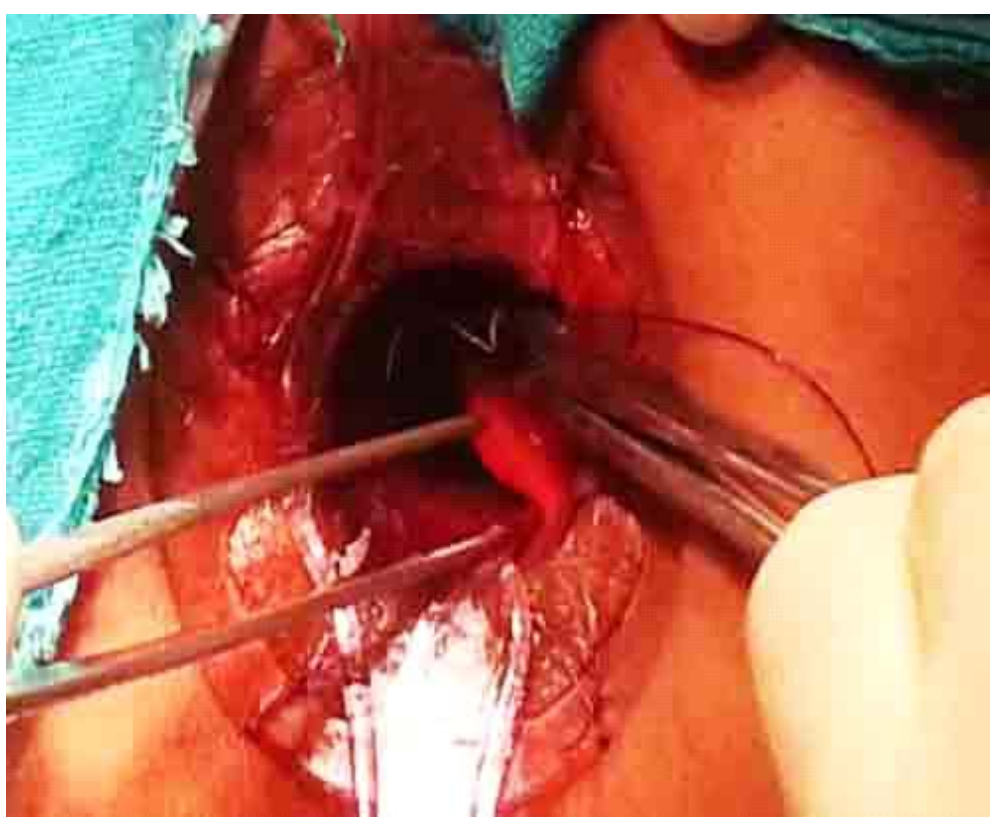

Figure 3. Taking mucosal bites through open end of the anoscope.

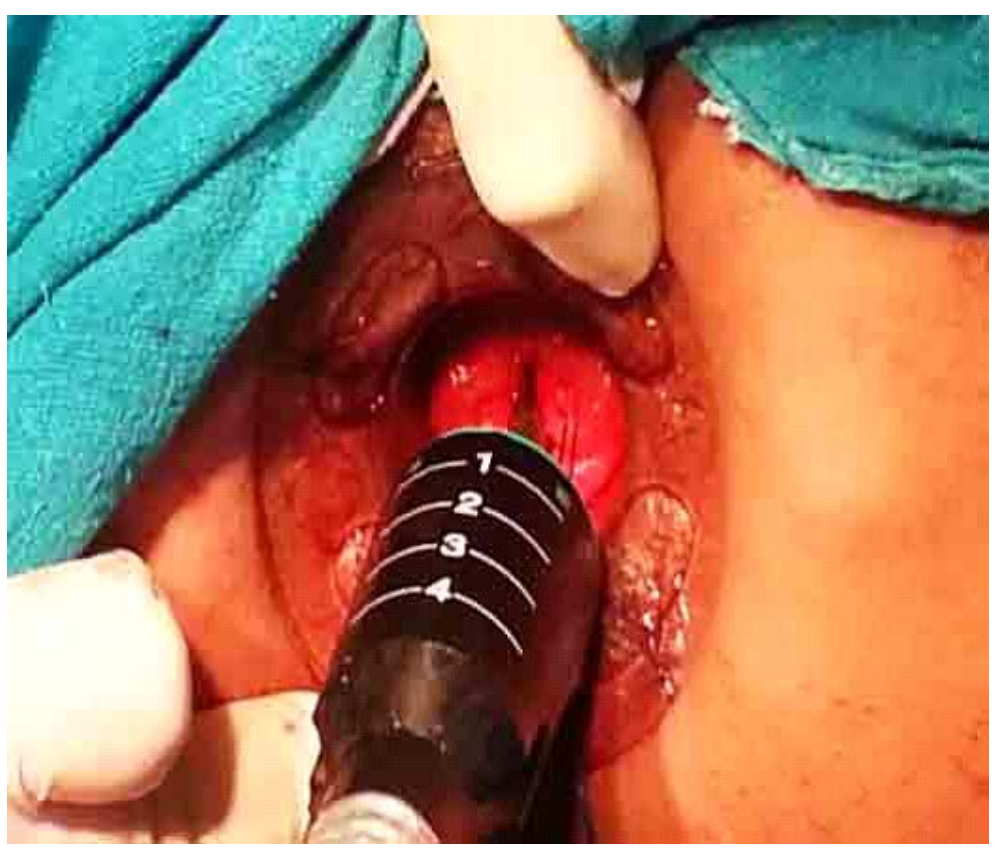

Figure 4. Anvil of the stapler introduced into the prolapsed mucosa.

over a period of time, however surgical treatment; Milligan Morgan conventional hemorrhoidectomy remained the standard of care for a very long time. The major concern about open hemorrhoidectomy has been the pain after the surgery and on that ground many patients would refuse surgery [3]. Multiple complimentary treatments have been proposed to reduce postoperative pain including use of different surgical instruments like diathermy scalpel, bipolar scissors, local or systemic injection of analgesics [4]. Lateral internal sphincterotomy has also been tried as a supplementary procedure to abate the pain due to sphincter spasm. In all these procedures the sensitive anal mucosa is severely traumatized during the removal of hemorrhoids. Then Longo proposed a minimal invasive procedure for hemorrhoids without damaging the sensitive ano rectum as the resection entails removal of a variable ring of insensitive mucosa above the anorectal junction [5] [6]. The results of this study 


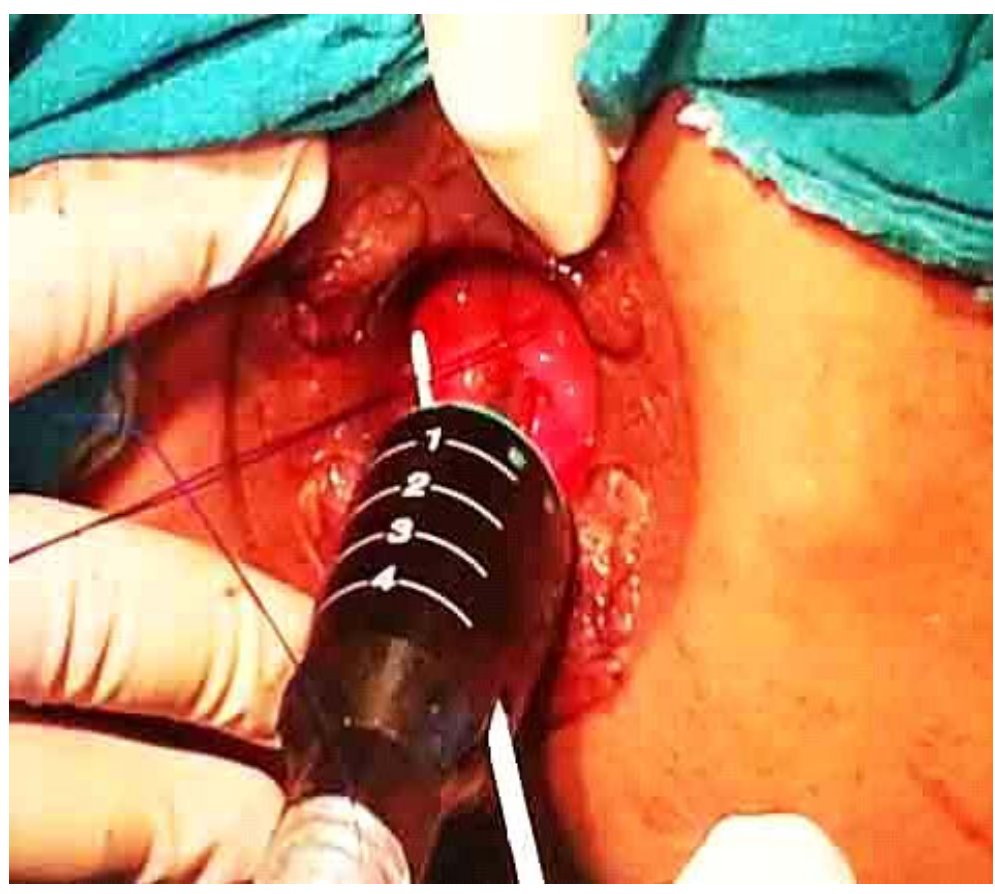

Figure 5. The sutures being fastened.

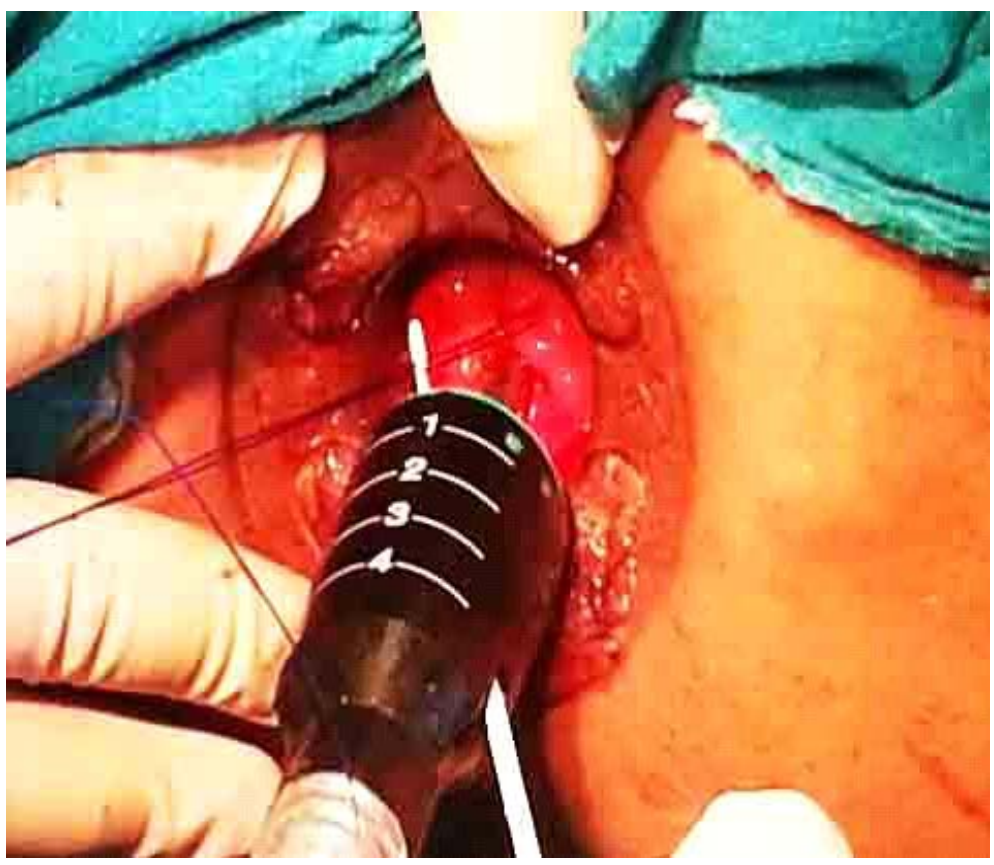

Figure 6. Stapler being fired.

have been quite satisfying with respect to postoperative morbidity i.e. pain, bleeding per rectum and early recovery. The incidence of early hemorrhage is not significantly lower than after conventional operation. We observed minimal intraoperative bleeding in 5 patients from the staple line which was controlled with over-sewing stitches. None of our patients required postoperative blood transfusion. Our study includes majority of males who had circumferential mucosal prolapse. We also included 7 patients who had undergone classical Milligan Morgan hemorrhoidectomy few years before and had relapsed. 8 of our patients developed postoperative retention that were managed by catheterization. Our study; with 6 months to one year follow-up shows comparative 


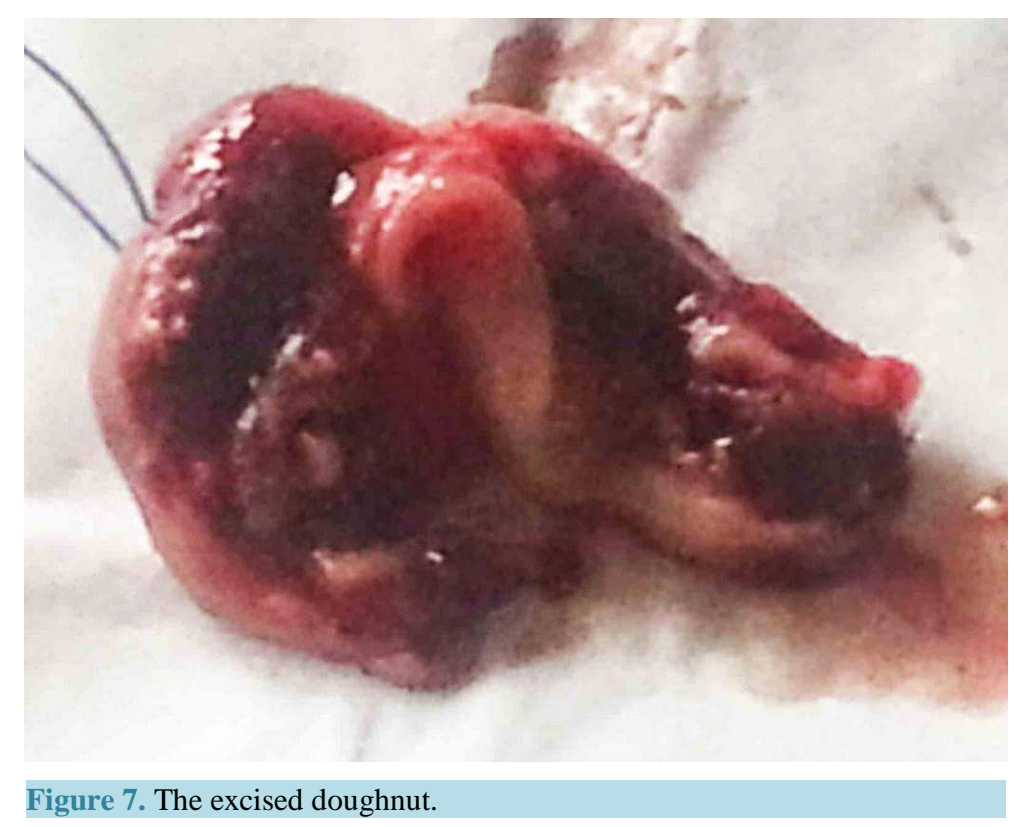

Table 1. Patient demographics and presentation.

\begin{tabular}{cl}
\hline Total No. of patients & 42 \\
\hline Males & 31 \\
\hline Females & 11 \\
\hline Presentation & \\
\hline Bleeding PR only & 03 \\
Discharge \& Itching & 17 \\
Prolapsed pile mass & 07 \\
\hline Bleeding with prolapsed mass & 15 \\
\hline
\end{tabular}

Table 2. Postoperative complications.

$\begin{array}{cc}\text { Retention of urine } & 08 \\ \text { Soiling on } 1^{\text {st }} \text { POD } & 07 \\ \text { constipation } & 04 \\ \text { Major postoperative bleed } & 00\end{array}$

results with open hemorrhoidectomy with reference to recurrence. The recurrence can occur as a result of incomplete doughnut harvesting which can be attributed to the technical failure due to skipping of a segment of rectal wall during the application of a purse-string suture [7] [8]. We would routinely take between 6 - 10 bites of purse-string suture before engaging the stapler. Another reason for an incomplete doughnut is due to spiral configuration of the purse-string due to slightly different entry and exit points while taking bites [8]-[10]. A useful technique of applying the purse-string sutures without anoscope has been described recently. This technique keeps a circumferential grip on the rectal mucosa and avoids any skip area in the staple line. We did not perform a second purse-string as already described by Longo because in our experience we did find it necessary [11] [12]. The theoretical benefits of this intervention are three folds. First the interruption of flow from the superior hemorrhoidal artery to the internal hemorrhoids may contribute to the improvement in hemorrhoidal symptoms by relieving vascular congestion. Secondly, partial excision of the hemorrhoidal cushions themselves 
reduces the size of the internal hemorrhoids. Thirdly, the resection of rectal mucosa reduces the tendency to prolapse and restores the internal cushions of Morgagni to their normal physiological positions [13].

\section{Conclusion}

Our study supports the evidence that stapled hemorrhoidectomy in Grade III/IV hemorrhoids is a safe and effective technique for the operative management of hemorrhoidal disease that can be performed as an ambulatory procedure. However, the study needs to be done on large volume basis to overcome the limitation of short sample size in our study.

\section{References}

[1] Longo, A. (1998) Treatment of Hemorrhoids Disease by Reduction of Mucosa and Hemorrhoidal Prolapse with a Circular Suturing Device: A New Procedure. Sixth World Congress of Endoscopic Surgery, Monduzzi Publishing Co., Rome, 777-784.

[2] Ho, Y.H., Cheong, W.K., Tsang, C., et al. (2000) Stapled Hemorrhoidopexy: Cost and Effectiveness. Randomized Controlled Trial including Incontinence Scoring, Anorectal Manometry, and Endoanal Ultrasound Assessments at up Three Months. Diseases of the Colon Rectum, 43, 1666-1675. http://dx.doi.org/10.1007/BF02236847

[3] Khalil, K.H., O’Bichere, A. and Sellu, D. (2000) Randomized Clinical Trial of Sutured versus Stapled Hemorrhoidopexy. British Journal of Surgery, 87, 1352-1355. http://dx.doi.org/10.1046/j.1365-2168.2000.01624.x

[4] Corman, M.L., Gravie, J.F. and Hager, T. (2003) Stapled Haemorrhoidopexy: A Consensus Position Paper by an International Working Party Indications, Contra-Indications and Technique. Colorectal Disease, 5, 304-310. http://dx.doi.org/10.1046/j.1463-1318.2003.00483.x

[5] Sultan, S., Rabahi, N., Etienney, I. and Atienza, P. (2010) Stapled Haemorrhoidopexy: 6 Years' Experience of a Referral Centre. Colorectal Disease, 12, 921-926. http://dx.doi.org/10.1111/j.1463-1318.2009.01893.x

[6] Katz, S., Down, T.D., Cash, H.R. and Grotz, R.C. (1970) Progress in the Development of the Index of ADL. Gerontologist, 10, 20-30. http://dx.doi.org/10.1093/geront/10.1_Part_1.20

[7] Pavlidis, T., Papaziogas, B. and Souparis, A. (2002) Modern Stapled Longo Procedure vs. Conventional Milligan-Morgan Hemorrhoidectomy: A Randomized Controlled Trial. International Journal of Colorectal Disease, 17, 50-53. http://dx.doi.org/10.1007/s003840100342

[8] Nystrom, P.O., Quist, N. and Rahaave, D. (2010) Randomized Control Trial of Symptom Control after Stapled Anopexy or Diathermy Excision for Hemorrhoidal Prolapsed. British Journal of Surgery, 97, 167-176. http://dx.doi.org/10.1002/bjs.6804

[9] Pasquale, G., Gianpiero, G., Roberto, S., Lauren, O. and Piero, N. (2009) Long-Term Outcomes of Stapled Hemorrhoidopexy vs. Conventional Hemorrhoidectomy: A Meta-Analysis of Randomized Controlled Trials. Archives of Surgery, 144, 266-272. http://dx.doi.org/10.1001/archsurg.2008.591

[10] Ceci, F., Picchio, M., Palimento, D., Calì, B., Corelli, S. and Spaziani, E. (2008) Long-Term Outcome of Stapled Hemorrhoidopexy for Grade III and Grade IV Hemorrhoids. Diseases of the Colon Rectum, 51, 1107-1112. http://dx.doi.org/10.1007/s10350-008-9333-1

[11] Lumb, K.J., Colquhoun, P.H., Malthaner, R. and Jayaraman, S. (2010) The Cochrane Library. Stapled versus Conventional Surgery for Hemorrhoids (Review), 9, 1-10.

[12] Avgoustou, C., Belegris, C., Papazoglou, A., Kotsalis, G. and Penlidis, P. (2014) Evaluation of Stapled Hemorrhoidopexy for Hemorrhoidal Disease: 14-Year Experience from 800 Cases. Minerva Chirurgica, 69, 155-166.

[13] Michalik, M., Pawlak, M., Bobowicz, M. and Witzling, M. (2014) Long-Term Outcomes of Stapled Hemorrhoidopexy. Videosurgery and Other Miniinvasive Techniques, 9, 18-23. http://dx.doi.org/10.5114/wiitm.2011.35784 